\title{
PERANCANGAN SISTEM INFORMASI DATA REKAM MEDIS PUSKESMAS KUMANIS KABUPATEN SIJUNJUNG DENGAN MENGGUNAKAN BAHASA PEMROGRAMAN VISUAL BASIC.NET
}

\author{
Elmawati $^{1}$, Veni Wedyawati ${ }^{2}$, Yulmi Sari ${ }^{3}$ \\ SekolahTinggiTeknologiIndustriPadang \\ Email: elmawati@sttind.ac.id ${ }^{1}$
}

\begin{abstract}
Abstrak: Pusat Kesehatan Masyarakat (Puskesmas) Kumanis Kabupaten Sijunjung saat ini sangat membutuhkan suatu sistem informasi yang akurat dan handal yang cukup memadai untuk meningkatkan pelayanan yang ada di puskesma kumanis kabupaten sijunjung terhadap para pasien yang datang berobat. Tujuan sistem ini dirancang adalah untuk membantu proses pengolahan data rekam medis menjadi lebih efektif dan dapat membantu karyawan dalam pencarian data riwayat kesehatan pasien dengan cepat dan mudah. Sistem rekam medis ini dapat membantu petugas medis puskesmas dalam memberikan tindakan medis dan menentukan obat yang akan diberikan kepada pasien mengatasi permasalahan yang ada dalam pengolahan data rekam medis di Puskesmas Kumanis yang saat ini masih menggunakan metode pencatatan manual yang belum efektif yaitu semua data- data dicatat di dalam sebuah buku. Dalam proses ini sistem yang berjalan belum optimal, karena masih ada sistem manual dalam pengerjaanya. Dengan cukup banyaknya pasien setiap harinya, dibutuhkan sebuah aplikasi yang bertujuan untuk membantu proses pengolahan data pasien. Oleh karena itu dibangunlah sebuah aplikasi pengolahan data pasien dengan menggunakan bahasa pemrograman Visual Basic. Net dan database MySQL.
\end{abstract}

Kata Kunci: Sistem Informasi, Rekam Medis Pasien, Visual Basic.Net

\begin{abstract}
Puskesmas Kumanis in Sijunjung District is currently in need of an accurate and reliable information system that is sufficient to improve the services available in the Kumanis Health Centre for patients who come for treatment. The purpose of this system is designed to help the process of processing medical record data become more effective and can assist employees in searching patient health history data quickly and easily. This medical record system can help health centre staff in providing medical treatment and determine the drugs to be given to patients to overcome the problems that exist in the processing of medical record data at the Kumanis Health Centre which currently still uses manual recording methods that have not been effective, such as: all data recorded in a book. In this process the system that is running is not optimal, because there is still a manual system in the process. With enough patients every day, we need an application that aims to help the processing of patient data. Therefore a patient data processing application was built using the Visual Basic programming language. Net and MySQL database.
\end{abstract}

Keywords: Information Systems, Patient Medical Records, Visual Basic. Net ]

\section{PENDAHULUAN}

Pendahuluan mencakup latar belakang Tujuan sistem ini dirancang adalah untuk mengatasi permasalahan yang ada dalam pengolahan data rekam medis di Puskesmas Kumanis, yang saat ini masih menggunakan metode pencatatan manual yang belum efisien, yaitu semua data-data dicatat di dalam sebuah buku.Belum adanya komputerisasi untuk pengolahan data rekam medis, pembuatan laporan dan penyimpanan data yang belum terstruktur karena belum menggunakan database. Dalam prosesini sistem yang berjalan belum optimal, kerena masih ada sistem manual dalam pengerjaanya. Dengan dukungan sistem komputerisasi,cara kerja suatu sistem yang 
sebelumnya manual dapat mengubah cara kerja yang lebih efisien, tepat guna dan berdaya guna serta terjamin mutu dan kualitas prosedur kerjanya. Dengan perkembangan sarana teknologi modern yang lebih baik, akan tercipta suatu lingkungan sistem kerja yang lebih produktif.

Perancangan sistem informasi tersebut dapat dilakukan dengan menggunakan beberapa bahasa pemrograman diantaranya Microsoft Visual Basic.Net, Database MySql. Mulyanto, Agus (2013)

Berdasarkan uraian latar belakang diatas, untuk permasalahan yang timbul maka penulis mencoba mengidentifikasikan permasalahan tersebut yaitu pencatatan data rekam medis masih menggunakan cara manual dan penyimpanan data rekam medis belum menggunakan sistem komputerisasi.

Untuk memfokuskan penelitian dan pembahasan maka perlu adanya batasan masalah yaitu penelitian ini mencakup tentang pengolahan data rekam medis yang ada di Puskesmas Kumanis. Dalam penelitian ini menggunakan bahasa pemrograman Visual Basic.Net dan database MySql.

\section{Tabel 1. Simbol Aliran Sistem informasi}

\begin{tabular}{|c|c|}
\hline SIMBOL & KETERANGAN \\
\hline & $\begin{array}{l}\text { Dokumen. Simbol ini digunakan untuk menggambarkan semua jenis } \\
\text { dolumen, merupakan formulir yang digunaksm untuk merekam data } \\
\text { terjadinya suatu tra usaksi, yang menunjulkan input dan output baik } \\
\text { untuk proses manual, mekanik, atsu komputer. }\end{array}$ \\
\hline & $\begin{array}{l}\text { Proses Manual. Simbol ini digunakan untuk menggambarkan kegiatan } \\
\text { manual atan pekejaan yang dilakukan tanpa menggunakan komputer. } \\
\text { Uraian singkat kegiatan manual dicantumban di dalam simbol ini. }\end{array}$ \\
\hline & $\begin{array}{l}\text { Proses Komputer / Online Computer Process. Simbol ini } \\
\text { menggamberkan kegiatan proses dari pegolahan data dengan komputer } \\
\text { secara online. Uraian singkat tentang operasi program komputer ditulis } \\
\text { di dalam simbol. }\end{array}$ \\
\hline & $\begin{array}{l}\text { Arsip. Simbol ini digunakan untukmenggambarkan file komputer / non } \\
\text { komputer yang disimpan sebagai arsip. Di dalam simbol ini bisa ditulis } \\
\text { huruf F atsu huruf A. }\end{array}$ \\
\hline & $\begin{array}{l}\text { Penghubung pada halaman yang sama. Simbol ini digunakan untuk } \\
\text { menunjukkan hubungan anus proses yang terputus masih dalam halaman } \\
\text { yang sams. Di dalam simbol ini dicantumkan nomor sebagai } \\
\text { penghubung. }\end{array}$ \\
\hline & $\begin{array}{l}\text { Penghubung pada halaman yang berbeda. Simbol ini digunakan } \\
\text { untul menunjulksan hubungan arus proses yang terputus dengan } \\
\text { sambungannya ada di halaman yang lain, sesuai dengan nomor yang } \\
\text { tercantum dalam simbol. }\end{array}$ \\
\hline & $\begin{array}{l}\text { Garis Alir. Simbol ini menunjulksan aliran/arah dari proses pengolahan } \\
\text { data. }\end{array}$ \\
\hline
\end{tabular}

Sumber : Sukamto, Rosa, Salahuddin, 2013
Tabel 2. Contex Diagram

\begin{tabular}{|c|c|}
\hline Simbol & Arti \\
\hline & Entity yang terlibat dalam sistem \\
\hline$\longleftarrow$ & Arah aliran data \\
\hline & Proses yang terjadi dalam sistem \\
\hline
\end{tabular}

Sumber :Kendall 2003

Tabel 3. Data Flow Diagram (DFD)

\begin{tabular}{|c|c|}
\hline SIMBOL & KETERANGAN \\
\hline & 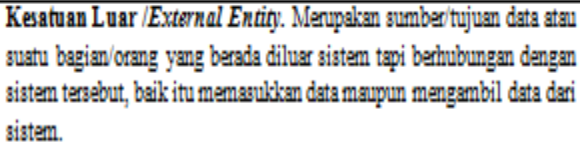 \\
\hline & 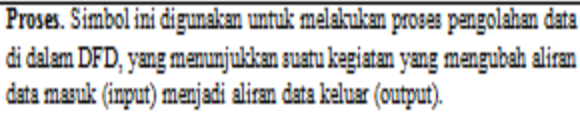 \\
\hline & $\begin{array}{l}\text { Penyimpanan Data / Data Store. Beffungsi sebggai tempat } \\
\text { panyimpanan dohumen-dohumen file-file yang dibutuhkan dalam suatu } \\
\text { sistem informasi. }\end{array}$ \\
\hline$\rightleftarrows \uparrow$ & $\begin{array}{l}\text { Aliran Data. Merunjulksan ans dalem prosas, dimanas simbol aliran date } \\
\text { ini mempunya nama tersendiri. }\end{array}$ \\
\hline
\end{tabular}

Sumber:Rosa $2013: 71$

Tabel 4. Simbol Activity Diagram

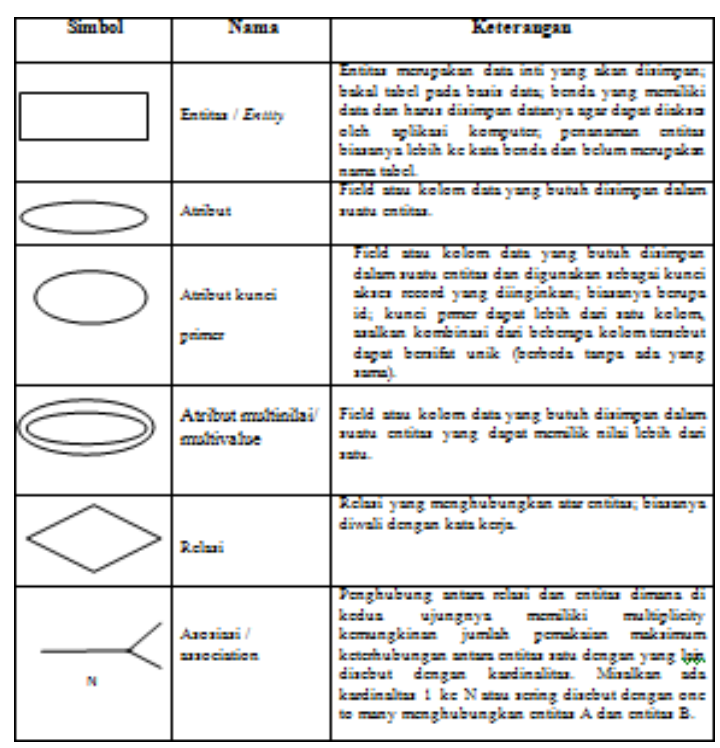

Sumber: Sukamto, Rossa dan Salahudin (2013) 


\section{METODE PENELITIAN}

Jenis penelitian yang penulis lakukan adalah penelitian Terapan (Applied research). Penelitian terapan adalah penelitian yang diarahkan untuk mendapatkan informasi yang dapat digunakan untuk memecahkan masalah. Penelitian terapan dilakukan dengan tujuan untuk menerapkan, menguji dan mengevaluasi masalah-masalah praktis sehingga dapat dimanfaatkan untuk kepentingan manusia baik secara individual maupunkelompok.

Pengumpulan data mencakup data primer yang didapat dengan metode wawancara (Interview) dan metode pengamatan (Observasi). Jogiyanto, H.M (2004) Sedangkan data sekunder diperoleh dari literatur, jurnal- jurnal dan studi kepustakaan yang berhubungan dengan penelitian.Veni Wedyawati, Elmawati, dan Khaerul Izmil Akhir (2018)

\section{Aliran sistem informasiLama}

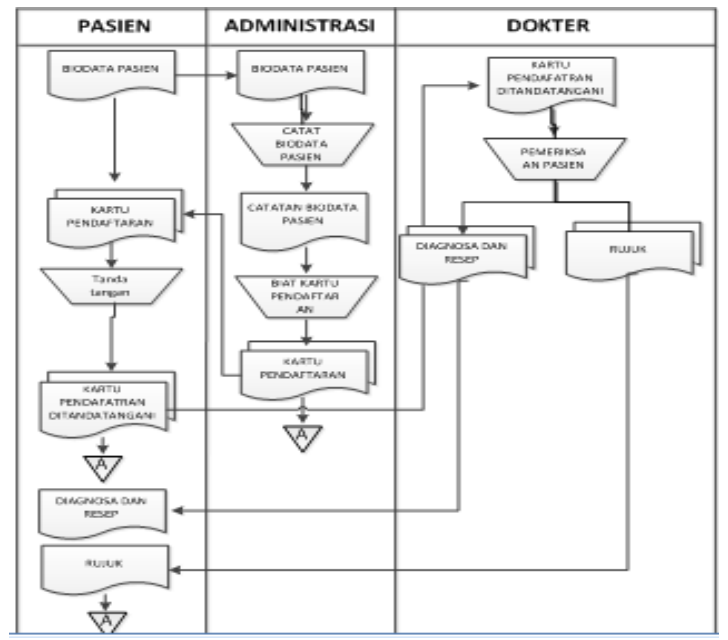

Gambar 1. Aliran sistem informasi lama

\section{Aliran Sistem InformasiBaru}

Pada aliran sistem informasi baru ini dilakukan beberapa perubahan dalam proses pengolahan data dan proses pembuatan laporan. Hal ini ditujukan agar kendalakendala pada sistem pengolahan data yang lama dapat diatasi, seperti pembuatan laporan data rekam medis serta data rujukan pasien diproses dengan menggunakan bantuan program applikasi.

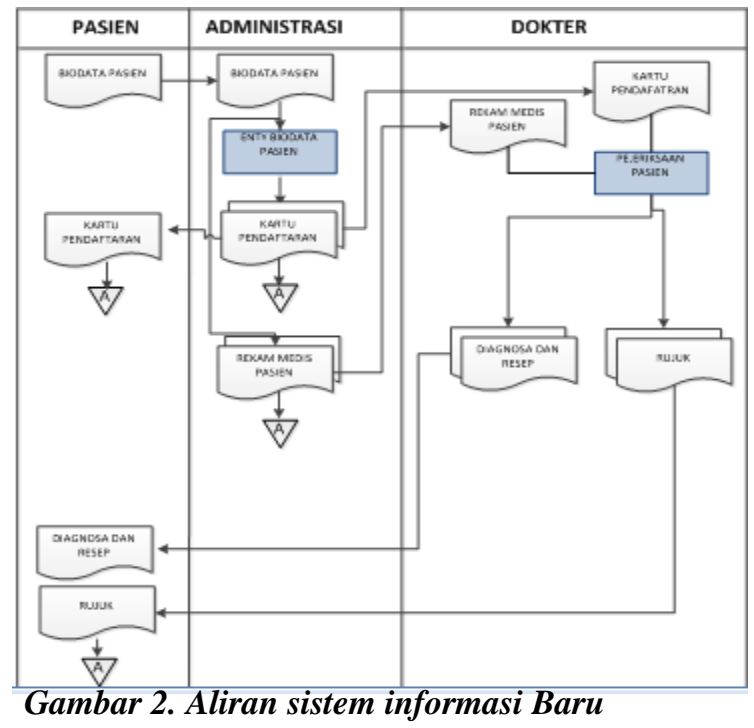

\section{Contex Diagram}

Context diagram adalah gambaran secara umum tentang suatu sistem yang terdapat di dalam suatu organisasi yang memperlihatkan batasan sistem, adanya interaksi antara eksternal entity dengan suatu sistem, dan informasi secara umum mengalir diantata entity dan sistem. Jogiyanto, H.M (2004)

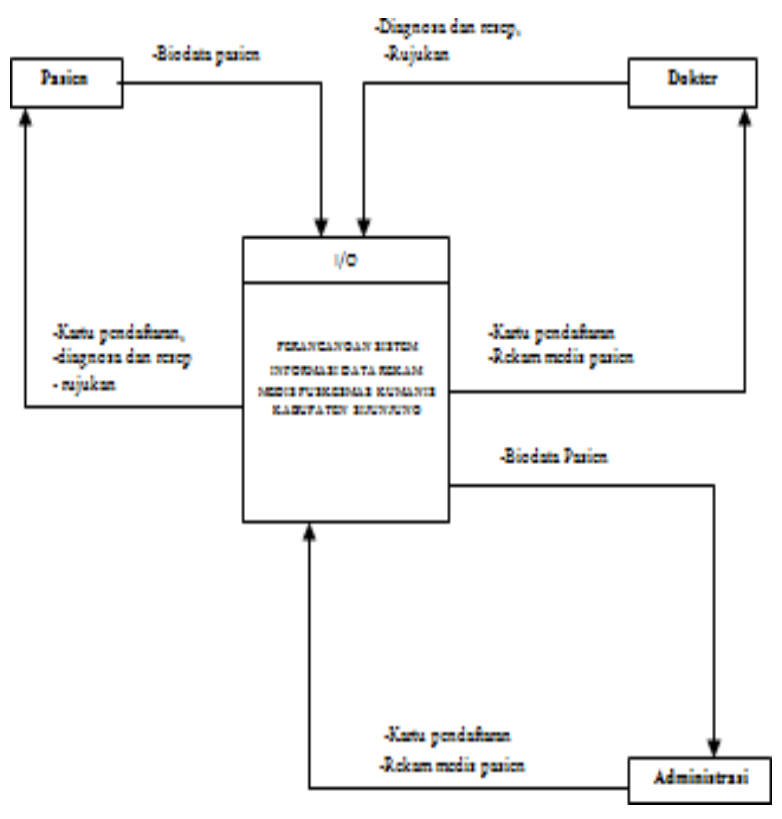

Gambar 3. Contex diagram 


\section{Data Flow Diagram}

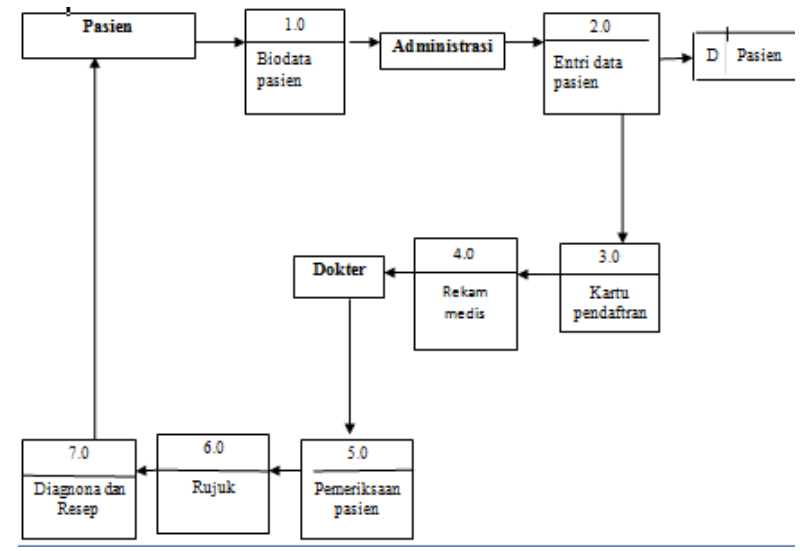

Gambar 4. Data Flow diagram

Data Flow Diagram (DFD) digunakan untuk menggambarkan arus data suatu sistem yang telah ada atau sistem baru yang akan dikembangkan secara logika. Jogiyanto, H.M (2004). Keuntungan dari pengguna DFD adalah memudahkan pemakai atau user yang kurang menguasai bidang komputer untuk mengerti sistem yang akan dikerjakan atau dikembangkan.

\section{Entity Relation Diagram (ERD)}

Entity Relatinship Diagram (ERD) merupakan suatu dokumentasi data dengan mengindentifikasikan entity data dan memperlihatkan hubungan yang ada diantara entity tersebut. Veni Wedyawati, Elmawati, dan Khaerul Izmil Akhir (2018)

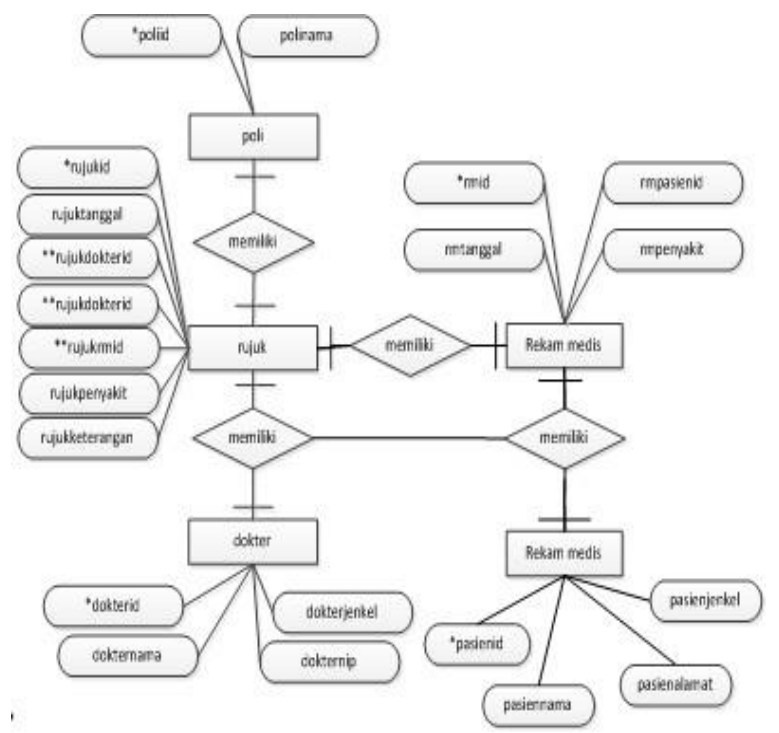

Gambar 5. Entity Relation Diagram

\section{HASIL DAN PEMBAHASAN \\ Implementasi Sistem Pengujian Sistem}

Pada pengujian sistem ini akan dilihat perbedaan antara sistem yang lama dengan sistem yang baru. Berikut merupakan penjelasan beserta gambar tentang " Perancangan Sistem Informasi Rekam Medis Puskesmas Kumanis Kabupaten Sijunjung dengan Menggunakan Bahasa Pemrograman Visual Basic.Net"

\section{Menu Login}

Pada tampilan menu login ini menampilkan user atau pengguna untuk masuk ke menuutama.

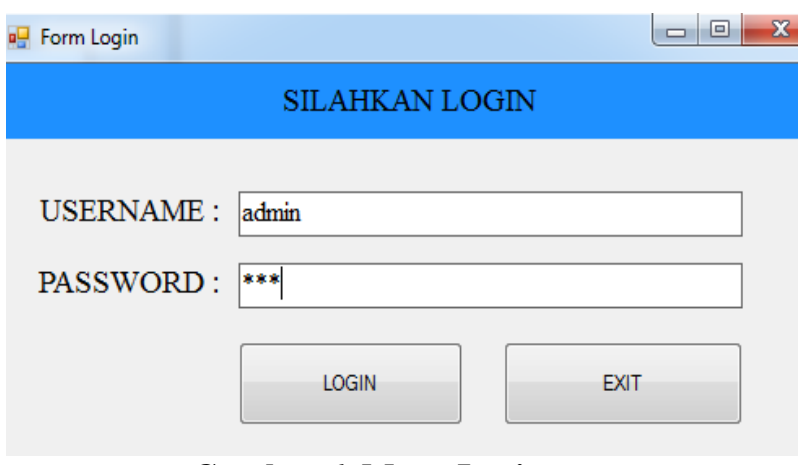

Gambar 6. Menu Login

\section{MenuUtama}

Pada tampilan menu utama ini menampilkan menu Master Data, Transaksi, Laporan, Logout yang dapat diakses user.

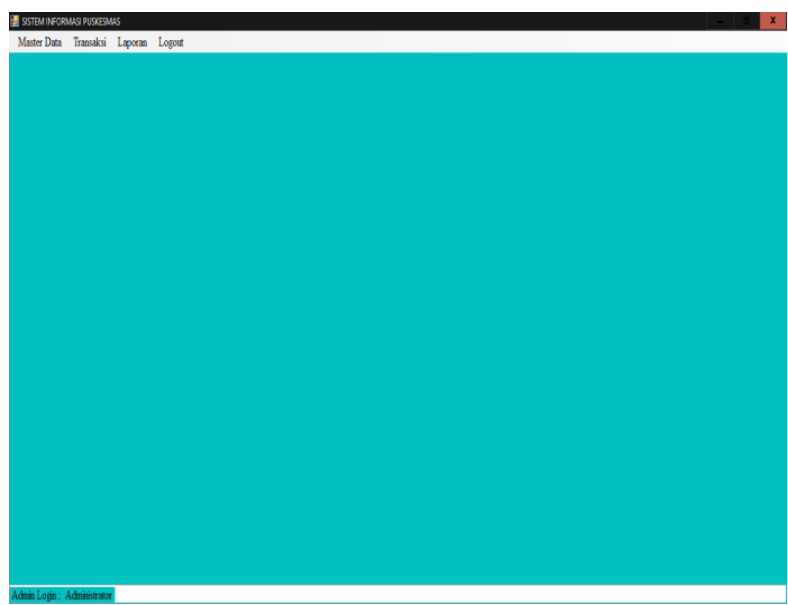

Gambar 7. Menu Utama 


\section{Menu Input Data Pasien}

Pada menu data pasien ini menampilkan data-data pasien yang berobat kepuskesmas Kumanis Kabupaten Sijunjung.

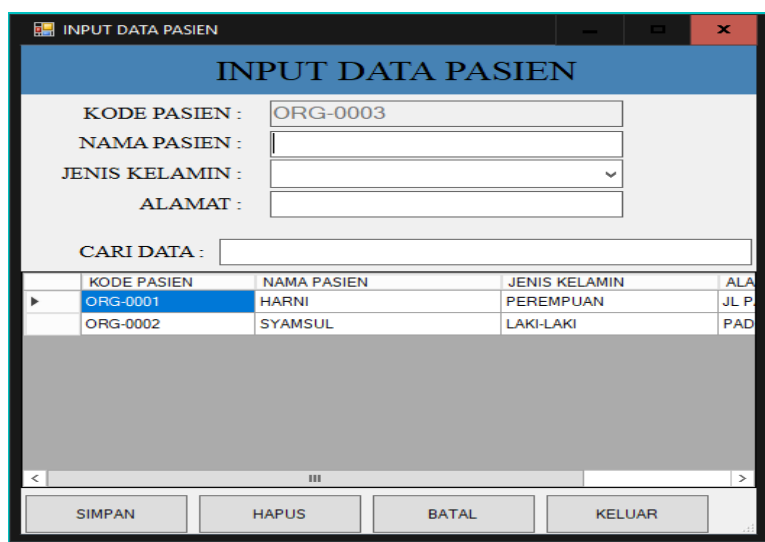

Gambar 8. Menu Input Data Pasien

\section{Menu Input DataDokter}

Pada halaman ini user bisa mengetahui data dokter di puskesmas Kumanis.

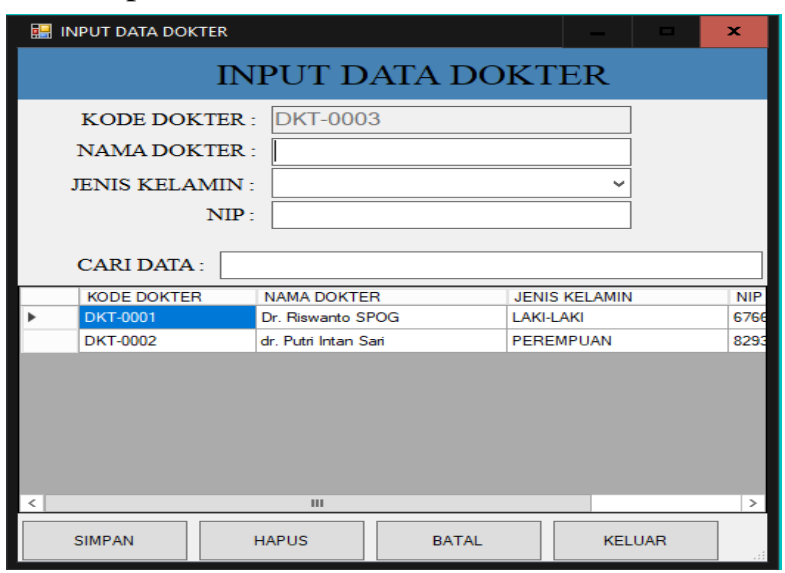

Gambar 9. Menu Data Dokter

\section{Menu Input DataPoli}

Pada menu ini admin menampilkan data poli di puskesmas Kumanis.

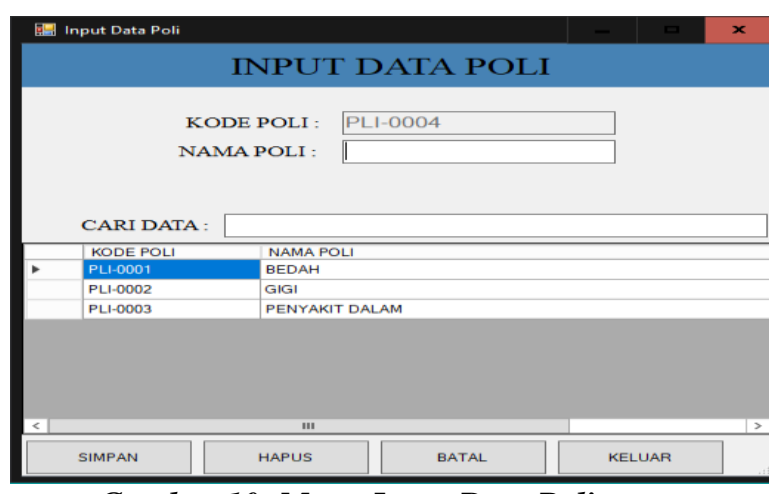

Gambar 10. Menu Input Data Poli

\section{Menu Data RekamMedis}

Pada menu ini admin menampilkan data data rekam medis puskesmas Kumanis.

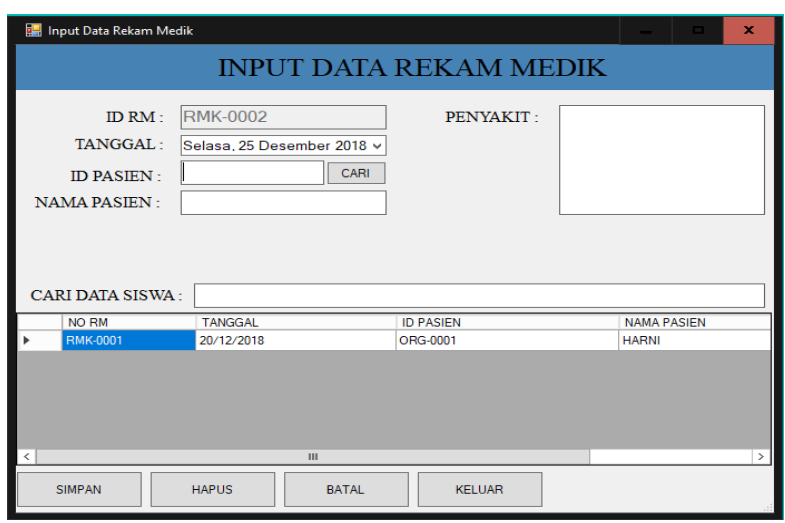

Gambar 11. Menu data rekam medis

\section{Menu datarujukan}

Pada menu ini menampilkan menu rujukan yang ada pada puskesmasKumanis.

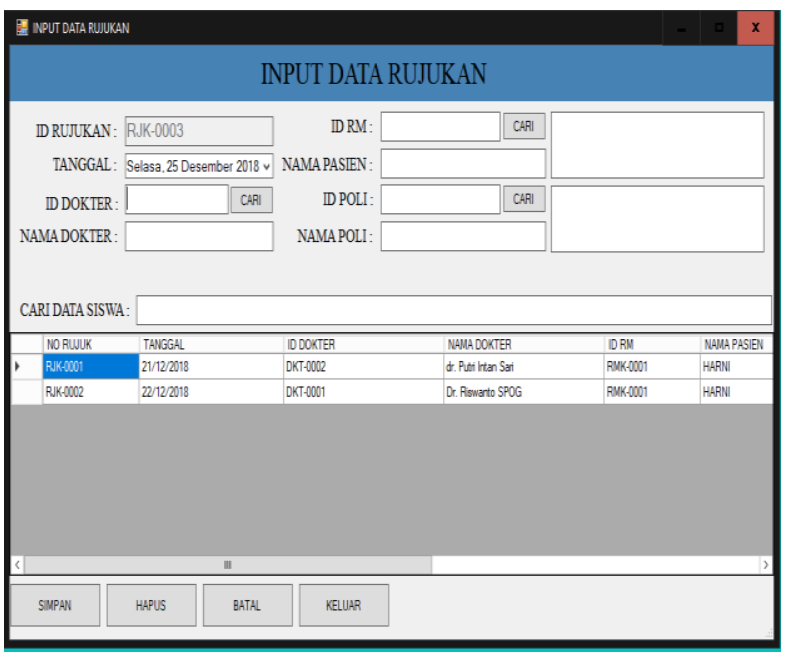

Gambar 12. Menu data rujukan

\section{Laporan Rekam Medis}

Pada tampilan ini menampilkan laporan rekam medis.

\begin{tabular}{l} 
Laporan Rekam Medis \\
\hline \begin{tabular}{|c|c|c|c|c|}
\hline Periode: Desember 2018 \\
\hline No & No Rekam Medis & Tanggal & Nama Pasien & Penyakit \\
\hline 1 & RMK-0001 & 20112/2018 & HARNI & Sesak nafas setelah makan \\
\hline
\end{tabular}
\end{tabular}

Gambar 13. Laporan Rekam Medis 


\section{Laporan DataRujukan}

Pada tampilan ini menampilkan laporan surat rujukan pada puskesmas kumanis.

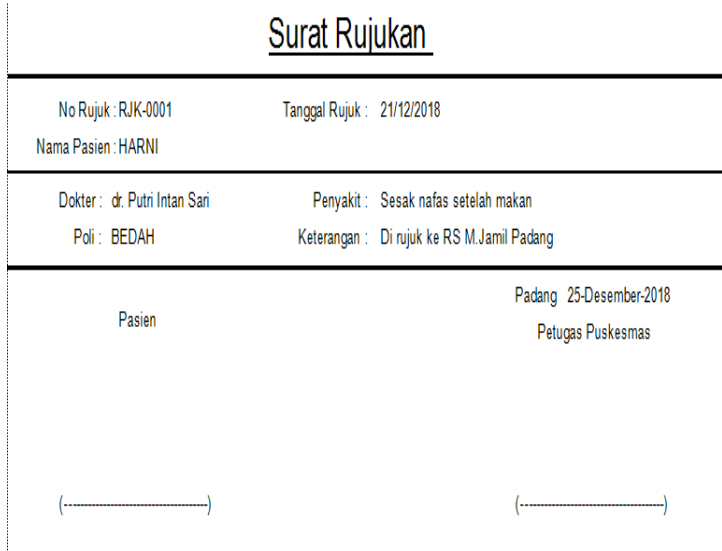

Gambar 14. Laporan Data Rujukan

\section{KESIMPULAN}

Berdasarkan penelitian yang telah dilakukan mengenai perancangan sistem informasi rekam medis di puskesmas kumanis kabupaten sijunjung dengan menggunakan bahasa pemrograman Visual Basic.Net di simpulkanbahwa:

1. Sistem ini dapat membantu petugas medis puskesmas dalam memberikan tindakan medis dan menentukan obat yang akan diberikan kepadapasien.

2. Membantu proses pengolahan data rekam medis menjadi lebihefektif.

3. Membantu petugas medis puskesmas dalam memberikan tindakan medis dan menentukan obat yang akan diberikan kepada pasien.

\section{DAFTAR PUSTAKA}

Jogiyanto, Analisis dan Desain Sistem Informasi, Penerbit Andi Offset.Yogyakarta, 2005.

Jogiyanto, H.M, Analisa Dan Desain Sistem Informasi, Penerbit Andi Offset. Yogyakarta, 2004.

Kendall, K.E \& Kendall, J.E, Al Hmdany Hafedh, Analisis dan Perancangan Sistem (jilid 1) edisi kelima, PT Prenhallindo dan Pearson Education Asia Pte.Ltd, Jakarta, 2003.
Leod,Mc, Sistem Informasi Manajemen, jilid 1, prentice Hall.inc, 1995

Mulyanto, Agus, Sistem Informasi Konsep dan Aplikasi, Penerbit pustaka pelajar, Yogyakarta,2009.

Musyofa, Aplikasi Data Pasien Pada Klinik K-24 Bandar Lampung, Cendikia, Bandar Lampung,2014.

O'Brien, A. James, Pengantar Sistem Informasi, Penebit Salemba 4, Jakarta,2005.

Soeherman Bonnie, Pinontoan marion, Designing Information System, Elek Media Komputindo, Yogyakarta, 2008

Sukamto, Rosa, Salahuddin, Rekayasa Perangkat Lunak, Informatika Bandung, Bandung, 2013

Veni Wedyawati, Elmawati, Khaerul Izmil Akhir. Perancangan Aplikasi Pengarsipan Surat Program Studi Sistem Informasi Pada Sekolah Tinggi Teknologi Industri Padang Menggunakan Vb Net 2010. Vol.18, No.1 Pg: 18-26.2018 